https://doi.org/10.30910/turkjans.725811

\begin{tabular}{c}
\hline \hline TÜRK \\
TARIM ve DOĞA BİLIMLERi \\
DERGISI \\
\hline \hline
\end{tabular}

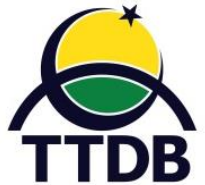

www.dergipark.gov.tr/turkjans

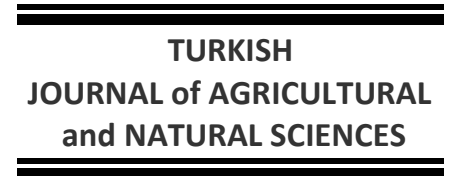

Araştırma Makalesi

\title{
Yapay Sulak Alanlarda Dolgu Malzemesi Seçimine Yönelik Kolon Test Çalışması ${ }^{\sharp}$ Fatma AKÇAKOCA* Zeki GÖKALP
}

Erciyes Üniversitesi, Ziraat Fakültesi, Biyosistem Mühendisliği Bölümü, Kayseri, Türkiye

*Sorumlu yazar: ftmaakcakoca@gmail.com

Geliş Tarihi: 20.09.2019 Düzeltme Geliş Tarihi: 28.02.2020 Kabul Tarihi: 05.03.2020

\begin{abstract}
Özet
Yapay sulak alan teknolojisi özellikle düşük arazi maliyeti ve sınırlı işgücüne sahip bölgeler için dünyanın birçok yerinde konvansiyonel arıtma yöntemlerine alternatif olarak geliştirilen arıtma teknolojileri arasında yer almaktadır. Ülkemiz koşulları dikkate alındı̆̆ında özellikle kırsal bölgelerde bu sistemler, atık su sorunlarının ekonomik ve sürdürülebilir çözümü için büyük önem arz etmektedir. Evsel nitelikli atık suların sulak alan ortamında oluşturduğu temel kirlilik besin elementleri (azot ve fosfor) yoluyla olmaktadır. Yapay sulak alan sistemlerinde temel fosfor giderim mekanizması ise ortam malzemesi tarafından adsorpsiyon yoluyla gerçekleşmektedir. Bu çalışmada Türkiye genelinde uygun bir fiyata doğal ve endüstriyel olarak üretimi yapılan zeolit ve pumis minerallerinin yapay sulak alanlarda ortam malzemesi olarak kullanılma olanakları laboratuvar koşullarında kolon denemeleri ile belirlenmiştir. Araştırmada iki malzemenin zeolit (Z) - pumis (P) ve bunların üç farklı karışım konusunun (\%(v/v) 75, 50 ve 25 ), üç dozda fosfor giriş konsantrasyonu (10, 20 ve 40 mg-l) ve dört farklı hidrolik alıkonma süreleri (1, 2, 3 ve 4 gün) sonunda elektriksel iletkenlik ve $\mathrm{pH}$ değişimleri ile toplam fosfor (TP) tutulma verimleri belirlenmiştir. Çalışma sonucunda pumis malzeme, diğer karışım konularına kıyasla oldukça düşük iletkenlik değişimi göstermiştir. Tüm ortamlarda pH değişimi ise giriş konsantrasyon değerlerine bağlı olarak artış göstermiştir. Toplam fosfor verimleri bakımından karışımda pumis malzeme oranı arttıkça fosfor giderim verimi artarken zeolit malzemenin fosfor giderim etkinliği daha düşük bulunmuştur.
\end{abstract}

Anahtar kelimeler: Doğal arıtma, dolgu malzemesi, filtrasyon

\section{A Column Test Study for Selection of Filling Material in Constructed Wetlands} Abstract

Constructed wetland technology is used as an alternative of conventional wastewater treatment systems in various parts of the world with low land costs and limited labor supply. In Turkey, constructed wetlands play a key role in economic and sustainable solution of wastewater problems especially of rural sections of the country. Domestic wastewater generally generate pollution through basic plant nutrients (nitrogen and phosphorus). Substrate adsorption is the principle phosphorus removal mechanism in constructed wetland systems. This study was conducted to investigate the phosphorus removal performance of zeolite and pumice minerals from domestic wastewaters. Filter column tests were conducted under laboratory conditions to assess the phosphorus removal performance of substrate materials. Zeolite and pumice materials were used alone and in mixtures $(\%(v / v) 75,50$ and 25$)$ and filter columns were subjected to three different phosphorus concentrations (10, 20 and $40 \mathrm{mg}-\mathrm{I})$ and four different hydraulic retention times (1, 2, 3 and 4 days). At the end of hydraulic retention times, effluent samples were taken, and EC, $\mathrm{pH}$ and TP tests were conducted on samples. The lowest variations in EC values were seen in pumice material. Increasing $\mathrm{pH}$ values were observed with increasing influent concentrations in all materials. Pumice exhibited greater phosphorus adsorption performance than zeolite and increasing phosphorus adsorption was observed with increasing pumice ratio in mixtures.

Key Words: Natural treatment, substrate material, filtration, adsorption 


\section{Giriş}

Atık su arıtımında dünyanın farklı yerlerinde çeşitli teknolojiler kullanılmaktadır. Bu teknolojiler fiziksel, kimyasal veya biyolojik süreçlerden oluşurken büyük oranda arıtım maliyetlerine bağlı olarak tercih edilmektedir. Doğal arıtma, doğal ortamlarda atık suların neden olduğu fiziksel, kimyasal veya biyolojik yollarla oluşan kirliliğin tutulması veya dönüştürülmesinde toprak, bitki ve mikroorganizma faaliyetlerinin gerçekleştiği süreç olarak bilinmektedir. Basit olarak doğal ortamlar sıvı ve katı atıkları özümleme güçleri sayesinde kolayca bertaraf etmektedirler. Yapay sulak alanlar ise doğal arıtmanın kontrollü bir biçimde gerçekleştiği sistemlerdir (EPA, 1993). Evsel ve endüstriyel atık su arıtımı için konvansiyonel arıtma sistemlerine bir alternatif olarak son yıllarda uygulanması hızla artan, enerji ihtiyacı az, yatırım ve işletme maliyetleri düşük, işletim şartları basit, çamur üretimi çok az, küçük ve orta ölçekli alanlarda kolaylıkla uygulanabilen doğal bir atık su arıtma sistemidir (EPA, 1993; EPA, 1999; Çiftçi ve ark., 2007). Bu sistemler, Devlet Planlama Teşkilatı tarafından açıklanan Kırsal Kalkınma Stratejilerinde ülke şartlarına en uygun arıtma/bertaraf teknolojilerinin uygulanması amacıyla "Kanalizasyon altyapısı ihtiyaçlarının giderilmesinde, yapım ve işletme giderleri düşük olan doğal arıtma tesislerinin yapımına öncelik verilecektir" ifadesiyle öncelikli alanlar olarak tanımlanmıştır (Anonim, 2006). Bu sayede düşük enerji, işçilik ve yatırım maliyetleri, bakım-izleme ve kullanım kolaylığı gibi avantajlara sahip bu sistemler Türkiye'de özellikle kırsal bölgelerde uygulama alanı bulmuştur. Diğer yandan yapay sulak alanların özellikle evsel atık suların yeniden kazanımı konusu Avustralya ve Güneydoğu Asya'da oldukça ilgiyle karşılanmaktadır (Sakadevan ve Bavor, 1998). Bu amaçla yapay sulak alan sistemlerinde süre gelen çalışmalar AKM, BOD ve çoğunlukla $\mathrm{N}, \mathrm{P}$ gibi besin elementlerinin gideriminde yoğunlaşmaktadır.

Atık suda fosfor inorganik ve organik formlarda fosfatlı bileşikler halinde bulunur. Yoğun olarak alg ve makro fitlerin kullanabileceği ortofosfat formundadır. Organik fosfor genelde biyolojik prosesler sonucunda oluşur ve ham atık suda gıda artıkları ve insan dışkısı olarak bulunur, inorganik fosfor ise genelde temizlik amacıyla kullanılan deterjanların sonucu oluşur, aynı zamanda fosfatlı gübrelerde önemli oranda inorganik fosfor içermektedirler. Sulak alanlarda fosfor giderimi fiziksel, kimyasal ve biyolojik arıtımı içeren çökelme, bitki alımı, tutulma gibi prosesler ile gerçekleşmektedir (Kadlec ve Knight, 1996; EPA, 1999). Atık sulardan fosforun arıtılması esnasında birden fazla süreç gerçekleşirken belirli bir kapasiteye sahip olana kadar giderim sağlanmaktadır. Bu düzeyden sonra ilave bir giderim meydana gelmemektedir (EPA, 1993). Bunun temel sebebi ortamda fosfor doygunluğunun oldukça hızlı gerçekleşmesidir. Bu nedenle evsel atık suların yapay sulak alanlar ile arıtımında özellikle fosfor gideriminde uzun süreli verim alınamamaktadır. Doğal arıtımda incelenen diğer tüm kirlilik giderim verimleri arasında fosfor gideriminin en düşük orana sahip olduğunu tespit eden Vymazal (1996) yapay sulak alanların alt tabakalarında uygun koşullar sağlandığında atık suda daha iyi fosfor giderimi sağlandığını belirtmektedir. Bu bağlamda geniş yüzey alanının yanında alüminyum, demir ve kalsiyum içeriği zengin olan killi bir dolgu malzemesinin fosfor giderim potansiyelleri oldukça yüksektir. Fakat düşük hidrolik iletkenliğe sahip kil, su ile teması zorlaştırmaktadır. Sulak alanlarda sıklıkla tercih edilen bir diğer dolgu malzemesi çakıllı malzemelerdir. Yüksek hidrolik geçirgenliğe sahip çakıllı malzeme oldukça küçük yüzey alanına sahip olması sebebiyle adsorpsiyon, iyon değişimi ve kimyasal reaksiyonda pasif bir etkinliğe sahiptir. Aktif olan yüzeylerin kapasiteleri dolduğunda fosfor giderimi hızla yavaşlayıp durmaktadır. Bu amaçla son yıllarda yapılan araştırmalar ise katı tutucu malzemeler kullanılmak suretiyle fosfor giderimi üzerine yoğunlaşmıştır. Nitekim sulak alanın fosfor giderim kapasitesini artırmak amacıyla kil, çakıl ve bazı endüstriyel atıklar denenmiştir. Yapay sulak alan dolgu malzemesi olarak sıklıkla çakıl malzeme kullanılmaktadır. Yüzeyaltı akışlı yapay sulak alan modeli kullanılarak yapılan bir çalışmada dolgu malzemesi olarak 3,5-10 mm arasında çakıl kullanılmış ve \%2-22 TP verim elde edilmiştir (Garcia ve ark., 2004). Dokuz farklı filtre malzemesinin fosfor adsorpsiyon karakteristikleri ve fiziko-kimyasal özellikleri üzerine bir araştırmada torf, üst toprak, çakıl, orta boy kum, yüksek fırın cürufu, kömür cürufu, yapay yüksek fırın cürufu, yapay kömür cürufu ve orta boy yapay kum malzeme denemişlerdir. Çalışma sonuçları torf malzemeyi en iyi fosfor emici malzeme olarak tespit etmişlerdir (Cui ve ark., 2008). Çalışmaların ortak sonucu ise fosfor 
gideriminde doğal malzemelerin başarılı olduğunu göstermektedir. Bu amaçla fosfor giderimi için ortam seçimi üzerine yapılan bir çalışmada fosforun kum malzeme üzerine adsorpsiyonu sulak alan sistemlerinde en önemli fosfor giderim mekanizması olarak gösterilmektedir. Kum malzeme seçiminin önemine değinilerek 13 farklı Danimarka kumunda fosfor giderim performansı üzerine çalışılmıştır. Araştırmacılara göre fosfor gideriminde kum malzemede aranan en önemli özellik Ca ihtivası olmuştur. Ayrıca fosfor bağlayıcı özelliği sebebiyle kalsit ve kırılmış mermerin oldukça yüksek kapasiteye sahip olduğuna değinilmiştir (Vymazal ve ark., 1998). Pumis açık renkli, boşluklu ve gözenekli, süngerimsi volkanik olaylar sonucu oluşmuş bir kayaç türüdür. Pumis tanelerinin fosfor adsorpsiyonu üzerine yapılan bir çalışmada \%80'in üzerinde bir fosfor giderimi etkinliği elde edip pumisin fosfor gideriminde umut verici bir tutucu olduğu ifade edilmiştir (Onar ve Öztürk, 1993). Njau ve ark., (2003), evsel atık suların arıtılması için kullanılan yapay sulak alanlarda filtre malzemesi olarak pumis kullanımı üzerine yaptıkları araştırmada, pumisin oldukça yüksek düzeyde bir fosfor giderim sağladığını ifade etmişlerdir. Zeolit bir alüminosilikat olup $(\mathrm{SiAl}) \mathrm{O}_{4}$ olup katyonları değiştirebilen, su molekülleri ile dolabilen gözenekler içeren dörtyüzlü bir moleküldür. Zeolit mineralleri adsorpsiyon, katyon değişimi, dehidrasyon-rehidrasyon ve kataliz gibi önemli özelliklere sahiptir. Catalfamo ve ark. (2006) düşük maliyetli bir ağır metal tutucu olarak zeolittli pumis minerallerinin kullanım olanaklarını değerlendirmişler ve söz konusu malzemenin atık sulardan metal iyonlarını kısa sürede giderdiğini ve izin verilen yasal limitlerin altına indirebildiğini, aktif karbon ve kitosan gibi yüksek maliyetli ağır metal tutucu malzemelerden daha iyi bir etkinlik sergilediğini ortaya koymuşlardır. Fosforun yapay sulak alan sistemlerinde bir dolgu malzemesi tarafından adsorpsiyonu ve/veya çökeltilmesi sonlu bir süreçtir. Kullanılan malzeme doygun hale geldiğinde yıkanması veya değiştirilmesi gerekmektedir. $\mathrm{Bu}$ nedenle bir malzemenin $\mathrm{P}$ tutma kapasitesinin bilinmesi veya farklı malzemeler ile karşılaştırılması için temel ve pratik bir analiz gerekmektedir (Mann, 1994). $\mathrm{Bu}$ amaçla uzun süreli kolon denemeleri ile malzemelerin fosfor tutma verimleri ve kapasiteleri incelenebilmektedir. Ayrıca bu yolla ortam olarak kullanılacak malzemenin ömrü belirlenebilir, bu parametre yapay sulak alanın tasarımında oldukça önemlidir (Mann, 1994).

Bu çalışmada yapay sulak alan sistemleri için evsel atık sulardan yüksek fosfor tutma oranı elde etmek amacıyla Kayseri bölgesi civarında yeterli rezervi bulunan zeolit ve pumis malzemeleri kullanılmıştır. Zeolit-pumis malzemelerin etkinliği laboratuvar ortamında filtre kolon testleri ile incelenmiştir.

\section{Materyal ve Metot}

\section{Materyal}

Araştırma deneyleri için Gördes Zeolit ve Garden Pomza'dan temin edilen dolgu malzemeleri, aynı boyut aralığında (0.5 - 4.0 $\mathrm{mm}$ ) Çizelge 1'de verilen hacimsel (v/v) karışım oranlarında karıştırılmıştır. Ayrıca filtre görevi görmesi amacıyla çakıl malzeme de araştırmada kullanılmıştır. Her kolonda ilk $10 \mathrm{~cm}$ çakıl malzeme olmak üzere $80 \mathrm{~cm}$ 'lik bölümü hazırlanan karışımlar ile doldurulmuştur (Şekil 1).

Çalışmada kolon denemesinde $(110 \mathrm{~mm}$ çapında ve $108 \mathrm{~cm}$ boyunda) toplam 30 kolon kullanılmıştır. Her biri zeolit ve pumis malzemelerin karışım oranlarında 10,20 ve 40 mg-P/l içeren sentetik çözelti (KH2PO4) ile yaklaşık $300 \mathrm{ml} /$ kolon olacak şekilde üstten beslenmiştir.

\section{Metot}

Araştırmada iki malzemenin zeolit (Z)pumis $(P)$ üç farklı karışım konusunun, 10, 20 ve $40 \mathrm{mg}$-I olmak üzere üç dozda fosfor giriş konsantrasyonu ve 1, 2, 3 ve 4 gün olmak üzere de dört farklı hidrolik alıkonma süreleri (HAS) sonunda elektriksel iletkenlik (EC), pH değişimleri ile toplam fosfor (TP) tutulma verimleri incelenmiştir. Hidrolik bekletme sürelerinin ardından alınan numunelerin fosfor düzeyleri ön denemelerinde 1-20 mg-l'nin üzerinde olduğundan fosfor analizleri için vanadomolibdofosforik asit kolorimetrik yöntem uygulanmıştır (Anonim, 1995). Numunelerde toplam ortofosfat tayini için kullanılan kolorimetrik metot için çözelti $A$ ve çözelti B reaktifleri kullanılmıştır. Ayrıca stok fosfor çözeltisi (KH2PO4) ile hazırlanan standart çözeltiler stok çözeltiden 250 ml'lik tüplere 1, 2, 4, 8, $10 \mathrm{mg}$-I olacak şekilde seyreltme yapılarak üzerine $5 \mathrm{ml}$ asit çözeltisi (Çözelti B) renk geliştirici olarak eklenmiştir. Kalan kısım saf su ile tamamlanmıştır. Hazırlanan örneklerden 1 $\mathrm{ml}$ alınarak bu işlemler tekrar edilmiştir. Renk 
gelişimlerini homojen hale getirmek için örnekler çalkalanmıştır.

Çizelge 1. Malzeme karışım oranları.

\begin{tabular}{lcc}
\multicolumn{1}{c}{ KONU } & Pumis karışım oranı (\%) & Zeolit karışım oranı (\%) \\
\hline 75P25Z & 75 & 25 \\
50P50Z & 50 & 50 \\
25P75Z & 25 & 75 \\
100P & 100 & - \\
100Z & - & 100 \\
\hline
\end{tabular}

Hazırlanan standart fosfor çözeltileri ile kalibrasyon eğrisi üzerinden spektrofotometre okumaları gerçekleştirilmiştir.

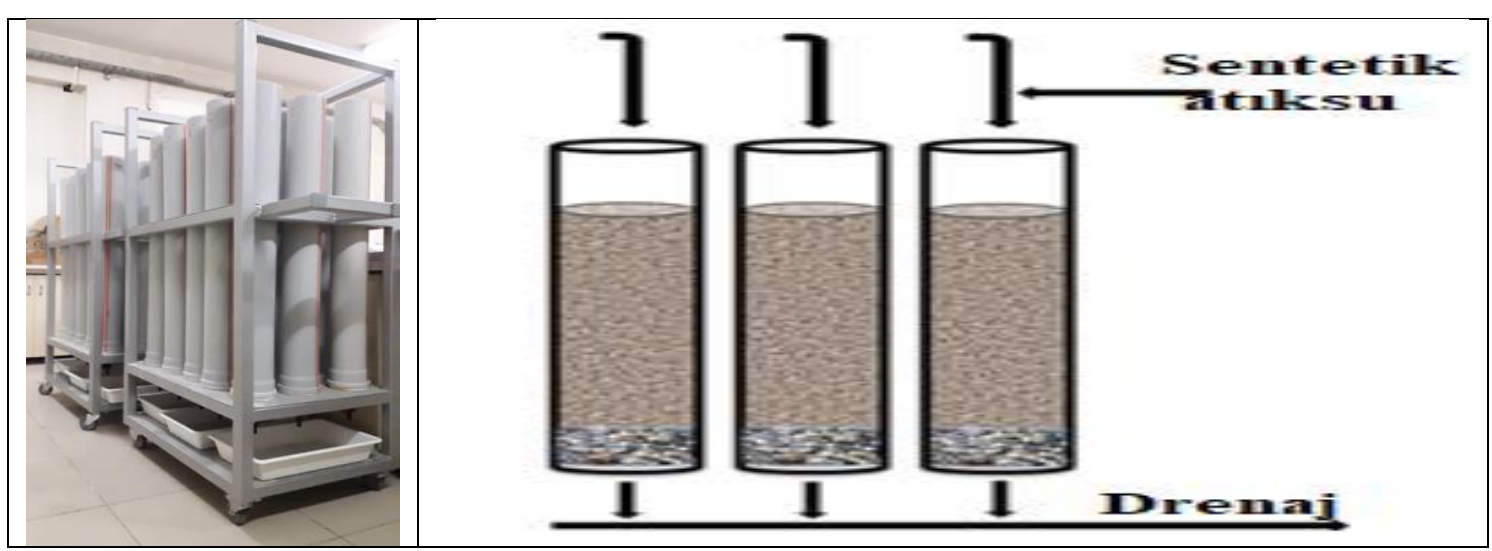

Şekil 1. Kolon test düzenekleri.

\section{Bulgular ve Tartışma}

Kullanılan sentetik atık suyun farklı konsantrasyonları $(10,20$ ve $40 \mathrm{mg}-\mathrm{l})$ için sırasıyla elektriksel iletkenlik değerleri 0,092, 0,155 ve $0,292 \mathrm{dS} / \mathrm{m}$ olarak ölçülmüştür. Hidrolik alıkonma sürelerinin ardından alınan numunelerin elektriksel iletkenlik değerlerinde ölçülen değişimler Şekil 2'de gösterilmiştir.

Şekil 2. incelendiğinde pumis malzeme ortalama 0,221 dS/m ile zeolit ve diğer karışım oranlarına kıyasla en düşük iletkenlik değerine sahip olurken, $75 \mathrm{P} 25 \mathrm{Z}$ ve 50P50Z karışım konularında 0,342 ve $0,349 \mathrm{dS} / \mathrm{m}$ ile en yüksek iletkenlik değeri gözlenmiştir. Bununla birlikte karışım konuları ve bekletme sürelerine göre değişen elektriksel iletkenlik değerlerinde bazı sapmalar haricinde sistemin verimini etkileyebilecek önemli bir değişim gerçekleşmemiştir. Ayrıca sentetik atıksuyun ortalama elektriksel iletkenlik değeri olan 0,180 $\mathrm{dS} / \mathrm{m}$ değeri, hidrolik bekletme süresi arttıkça yükselmeye başlamış ve pumis hariç tüm malzemelerde $0,300 \quad \mathrm{dS} / \mathrm{m}$ değerine yaklaşmıştır. Bunun temel nedeni bekletme süreleri arttıkça değişen fosfor tutma verimi ile çözünmüş forma geçmeye başlayan kirletici konsantrasyonunun atıksuyun iletkenliğini artırmasıdır (Reedy ve D’Angelo, 1994). Kullanılan sentetik atık suyun farklı konsantrasyonları $(10,20$ ve $40 \mathrm{mg}-\mathrm{I})$ için $\mathrm{pH}$ değerleri $6,22,6,27$ ve 6,14 olarak ölçülmüştür. Çıkış numunelerinde hidrolik alıkonma süreleri dikkate alınarak $\mathrm{pH}$ değişimi değerlendirilmiştir. Sırasıyla 1, 2, 3 ve 4 günlük hidrolik alıkonma süreleri sonunda elde edilen değişimler Şekil 3'de verilmiştir. 

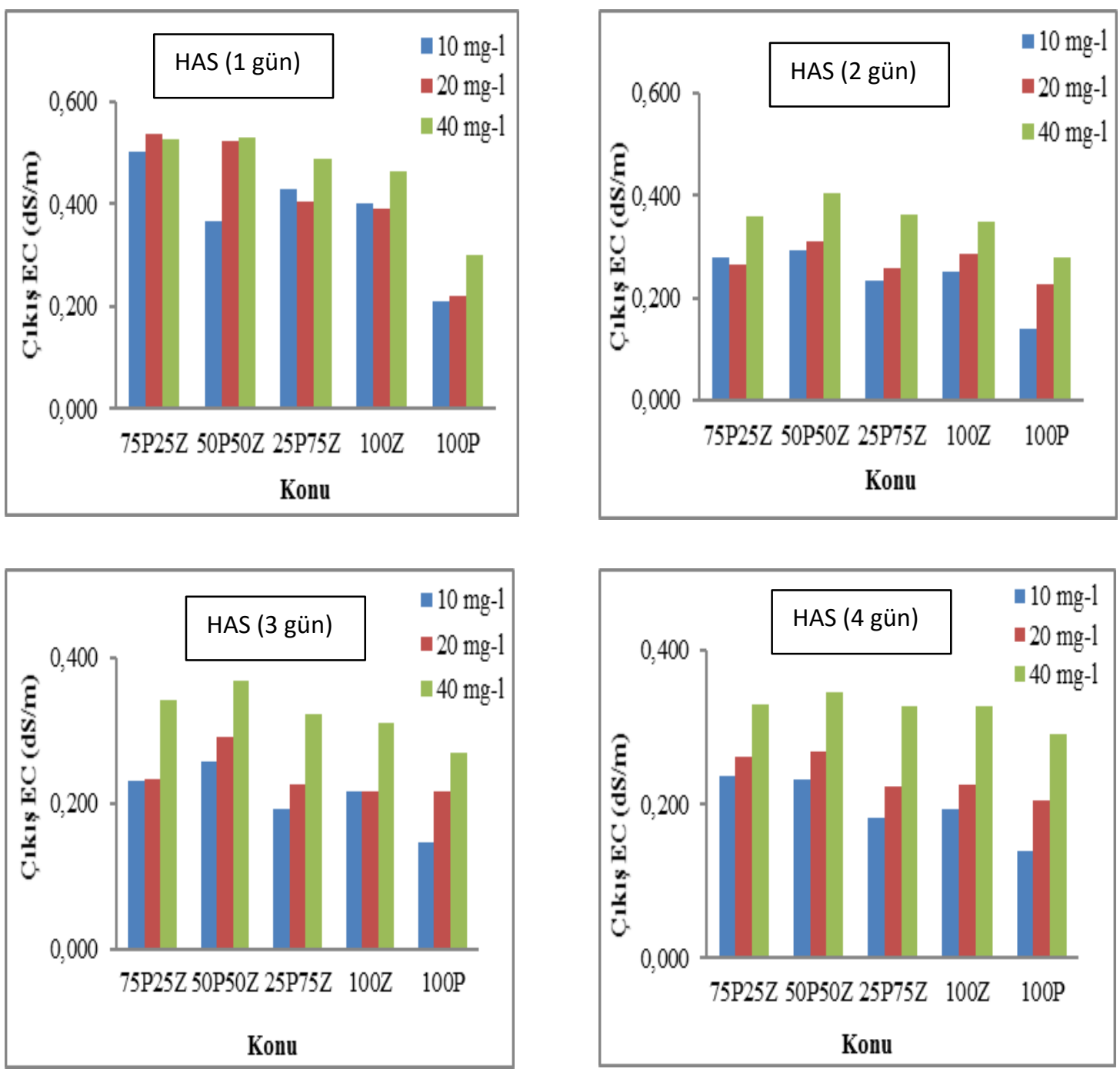

Şekil 2. Hidrolik alıkonma sürelerine bağlı EC değiş̧imi.

Şekil 3'deki göstergeler değerlendirildiğinde 75P25Z karışım konusu $7,50 \mathrm{pH}$ değeri ile atıksuyun ortalama $\mathrm{pH}$ değeri olan 6,21 değerinden oldukça farklılık gösterirken, bu karışım konusunu sırasıyla 50P50Z, 25P25Z, $100 Z$ izlemektedir. Diğer taraftan pumis malzeme 6,08 ile atıksuyun $\mathrm{pH}$ değerine en yakın sonucu vermiştir. Sonuçlar fosfor tutma verimleri ile ilişkilendirildiğinde çıkış pH değerleri ile fosfor tutulma performansları arasında doğrusal bir ilişki gözlenmemiştir. Yüksek $\mathrm{pH}$ değerlerinin malzemenin tutunma yüzeyi üzerinde oluşturduğu etkiler ile adsorpsiyon oranını artırdığı belirtilmektedir (Eckenfelder, 1968).

Ayrıca literatürde çoğu araştırmacı pH'nın atıksudaki kirleticilerin gideriminde etkili olduğu görüşünde birleşmişlerdir. Bu görüşler yalnızca en yüksek $\mathrm{pH}$ değeri ile yüksek fosfor tutma performansı göstermiş olan 75P25Z için doğrulanmıştır. Filtre kolon testleri ile pumiszeolit malzemelerin belirlenen boyut aralığında (0.5- $4.0 \mathrm{~mm}$ ) iki malzemenin ve bunların üç farklı karışım konusunun (\%75,50 ve 25), üç farklı giriş konsantrasyonu $(40,20$ ve $10 \mathrm{mg}$ $\mathrm{P} / \mathrm{L}$ ) ve dört farklı hidrolik alıkonma süreleri (1, 2,3 ve 4 gün) sonunda Toplam fosfor tutulma verimleri Çizelge 2 ile Şekil 4 ve $5^{\prime}$ de birlikte verilmiştir. 

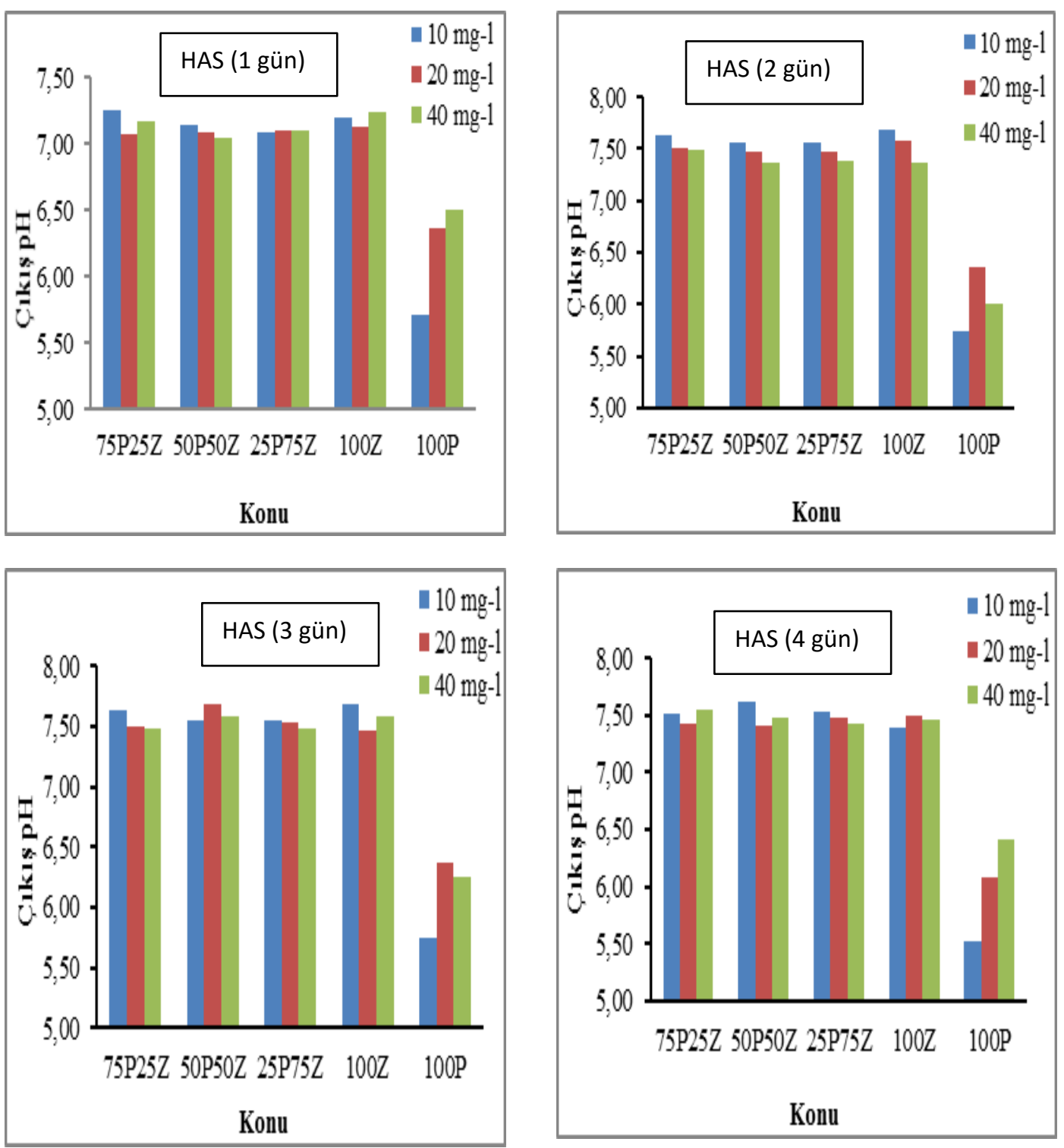

Şekil 3. Hidrolik alıkonma sürelerine bağlı pH değişimi.

Çizelge 2 ve Şekil 4 ve 5 birlikte incelendiğinde atıksuyun giriş fosfor konsantrasyonu ortalama 23,3 mg-I iken sırasıyla 75P25Z konusunda 9,3 mg-l, 50P50Z konusunda 10,4 mg-I, 25P75Z konusunda 11,6 mg-l, $100 \mathrm{Z}$ konusunda $11,6 \mathrm{mg}-\mathrm{l}$ ve $100 \mathrm{P}$ konusunda $10,08 \mathrm{mg}-$ I ortalama çıkış konsantrasyonu elde edilmiştir. Sonuçlara göre toplam hidrolik bekletme süresi sonunda en yüksek fosfor tutma oranına sahip malzeme $100 \mathrm{P}$ ve zeolit-pumis karışımlarında ise $75 \mathrm{P} 25 \mathrm{Z}$ kombinasyonunda olurken, diğer konulardaki sonuçlarda birbirine oldukça yakın ve yüksek fosfor tutma performansı göstermişlerdir. Doğal arıtımda incelenen diğer tüm kirlilik giderim verimleri arasında fosfor gideriminin en düşük orana sahip olduğunu tespit eden Vymazal (1998) bu sistemlerdeki fosfor giderim etkinliğinin artırılmasında sulak alan ortam malzemesinin $\mathrm{Ca}$, Fe ve $\mathrm{Al}$ içeriğine bağlı olduğunu belirtmiştir. Araştırma deneyleri için değerlendirilen Gördes Zeolit ve Garden Pomzadan temin edilen dolgu malzemelerin fiziksel ve kimyasal özellikleri firmalardan sağlanmıştır. Malzemelerin $\mathrm{SiO}_{2}, \mathrm{Ca}, \mathrm{Al}_{2} \mathrm{O}_{3}$ ve $\mathrm{Fe}_{2} \mathrm{O}_{3} \quad$ içerikleri zeolit için sırasıyla $\% 72, \% 1, \% 13, \% 2$ ve pumis için bu değerler \%54, \%14, \%11 ve \%3'tür. Buna göre pumis malzeme Ca içeriği zeolite oranla daha yüksektir fakat her iki malzemenin mineral içeriği nerdeyse aynı olduğu görülmektedir. Yapay sulak alanlar evsel atık su 
arıtımında \%92-95 askıda katı madde (AKM), \%80-99 biyolojik oksijen ihtiyacı (BOi), \%30-80 toplam azot (N), \%20-70 toplam fosfor (TP) giderim performansı göstermektedir. Bu değerler tercih edilecek bitki, dolgu malzemesi ve yapay sulak alanın akım tipine bağlı olarak değişiklik göstermektedir. Yapılan çalışmalarda kireçtaşı, cüruf, çakıl, kil agregaları (LECA) ve diğer suya dayanıklı malzemeler değerlendirilmiştir (Mann,
1994). Ayrıca yüksek fırın cürufu, zeolit ve killi malzemeler tek başına veya toprakla kombinasyonları halinde kullanılarak $\mathrm{P}$ tutma kapasiteleri artırılmıştır (Sakadevan ve Bavor, 1998). Bu sistemlerde sıklıkla kullanılan çakıl malzemenin ise fosfor tutma kapasitesi genellikle düşüktür. Kullanılan farklı malzemeler ile fosfor tutma oranı geniş ölçüde artırılabilmektedir (Vymazal ve ark., 1998).

Çizelge 2. Karışım konularında meydana gelen fosfor adsorpsiyonu.

\begin{tabular}{|c|c|c|c|c|c|c|}
\hline \multirow{2}{*}{$\begin{array}{l}\text { Giriş fosfor } \\
\text { kons. (mg-l) }\end{array}$} & \multicolumn{3}{|l|}{ Konu** } & \multicolumn{3}{|c|}{ Çıkış fosfor kons. (mg-l) } \\
\hline & HAS* (gün) & 1 & 2 & 3 & 4 & Ortalama \\
\hline \multirow{5}{*}{10} & 75P25Z & 3,20 & 3,90 & 6,57 & 5,41 & 4,77 \\
\hline & 50P50Z & 4,19 & 3,36 & 6,00 & 5,07 & 4,66 \\
\hline & 25P75Z & 2,92 & 4,52 & 7,15 & 6,95 & 5,38 \\
\hline & $100 Z$ & 2,48 & 4,54 & 8,64 & 8,67 & 6,08 \\
\hline & $100 \mathrm{P}$ & 4,58 & 5,70 & 7,94 & 8,77 & 6,75 \\
\hline \multirow{5}{*}{20} & 75P25Z & 4,17 & 12,22 & 10,69 & 10,36 & 9,36 \\
\hline & 50P50Z & 5,48 & 6,82 & 9,13 & 10,24 & 7,92 \\
\hline & 25P75Z & 6,24 & 10,60 & 12,27 & 13,38 & 10,62 \\
\hline & $100 Z$ & 5,96 & 9,32 & 10,19 & 12,73 & 9,55 \\
\hline & $100 P$ & 7,10 & 7,66 & 11,29 & 12,68 & 9,68 \\
\hline \multirow{5}{*}{40} & 75P25Z & 9,20 & 9,20 & 18,42 & 18,51 & 13,83 \\
\hline & 50P50Z & 15,34 & 15,34 & 21,62 & 22,39 & 18,67 \\
\hline & $25 P 75 Z$ & 13,74 & 13,74 & 23,65 & 24,48 & 18,90 \\
\hline & $100 Z$ & 13,95 & 13,95 & 23,06 & 25,09 & 19,02 \\
\hline & $100 P$ & 10,45 & 12,13 & 16,04 & 16,59 & 13,80 \\
\hline
\end{tabular}

*HAS: Hidrolik Alıkonma Süresi (gün) **karışım konuları (\%v/v) 75 pumis-25 zeolit, 50 pumis-50 zeolit, 25 pumis-75 zeolit, 100 zeolit, 100 pumis

\section{Sonuçlar ve Öneriler}

Yapay sulak alanlardaki fosfor tutma kapasitesi araştırması için birçok filtre malzemesi kullanılmasına rağmen çoğu ortam ekonomik verimlilik ve gerçek alana uygulanabilme kolaylığı bakımından sınırlı olmuştur. Bu nedenle kum ve çakıl kullanıldığı araştırmalar sıkça yapılmıştır. Bununla birlikte kumun fosfor adsorpsiyon kapasitesi bölgeye ve fiziko-kimyasal özelliklerine bağlı olarak değişiklik göstermiştir. Bu nedenle gerçek yerel uygulamalar için uygun filtre ortamının seçilmesine gerek olduğuna karar verilmiştir.
Özellikle hem ekonomik verimliliği hem de kolaylığı sağlamak için yüksek adsorpsiyon kapasitesine sahip filtre ortamı seçimi oldukça önemlidir. Sunulan araştırmanın sonuçlarına göre Kayseri bölgesi ve civarı için kurulacak yapay sulak alan sistemlerinde ortam malzemesi olarak pumis malzemenin kolay ve ucuz erişilebilirliği ve laboratuvar ölçekli deneylere göre yüksek fosfor tutma performansı sağlaması sebebiyle kullanılabilir olduğu fakat malzeme etkinliğinin adsorpsiyondesorpsiyon testleri ve saha çalışmaları sonucunda tam olarak anlaşılabileceği sonuçlarına ulaşılmıştır. 


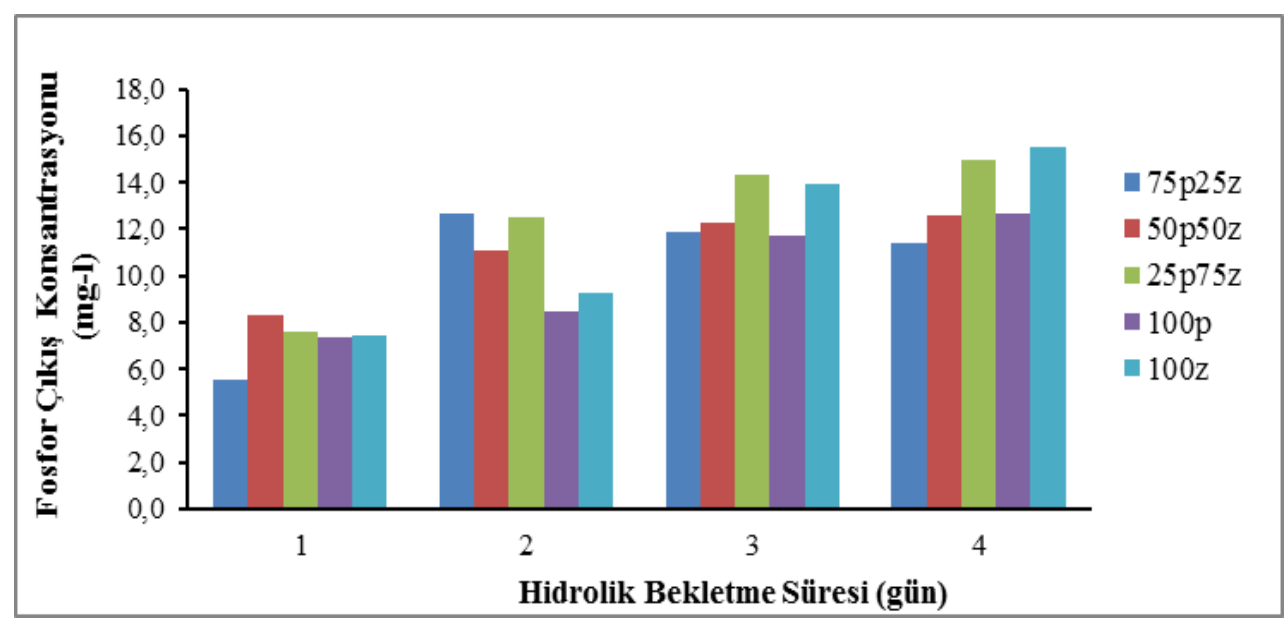

Şekil 4. Hidrolik bekletme sürelerine göre karışım konularındaki fosfor adsorpsiyonu.

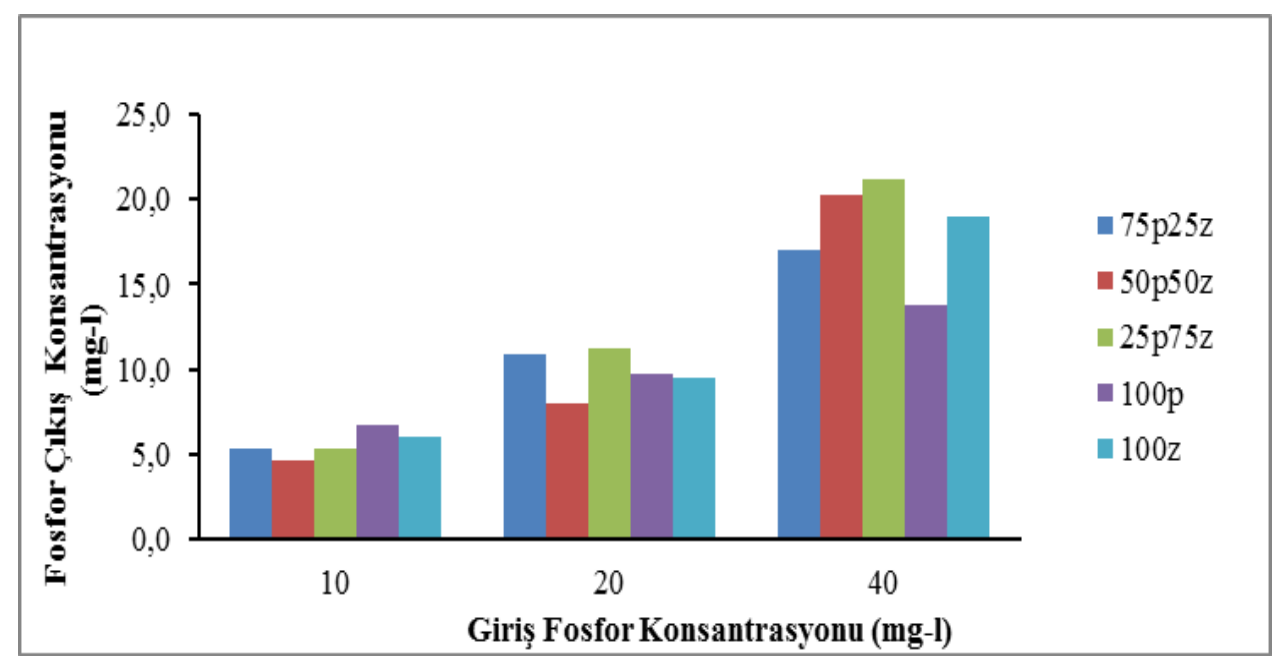

Şekil 5. Giriş fosfor konsantrasyonlarına göre karışım konularındaki fosfor adsorpsiyonu.

*: Bu çalışma Erciyes Üniversitesi Fen Bilimleri Enstitüsü Biyosistem Mühendisliği Anabilim Dalı öğrencisi Fatma AKÇAKOCA'nın Yüksek Lisans Tez'inden hazırlanmıştır.

\section{Kaynaklar}

Anonim, 1995. Standard methods for the exemination of water and wastewater, American Water Works Association/American Public Works Association/Water Environment Federation, 19th Edition, USA.

Anonim 2006. Ulusal Kalkınma Stratejisi, Devlet Planlama Teşkilatı, (sgb.tarim.gov.tr).

Catalfamo, P., Arrigo, I., Primerano, P., ve Corigliano, F., 2006. Efficiency of a zeolitized pumice waste as a low-cost heavymetals adsorbent. Journal of hazardous materials, 134(1-3), 140-143.

Cui, L., Zhu, X., Ma, M., Ouyang, Y., Dong, Mei, Zhu, W., Luo, S., 2008. Phosphorus Sorption Capacities and Physicochemical Properties of Nine Substrate Materials for Constructed Wetland. Archives of Environmental Contamination and Toxicology, 55: 210-217.

Çiftçi, H., Kaplan, Ş.Ş., Köseoğlu, H., Karakaya, E., Kitiş, M., 2007. Yapay sulakalanlarda atıksu arıtımı ve ekolojik yaşam, Erciyes Üniversitesi Fen Bilimleri Enstitüsü Dergisi, 23 (1-2): 149-160.

Eckenfelder, W.W., 1968. Manual of Treatment Processes: Principles and applications of adsorption. Water Resource 
Management Series, No: 1, s. 1-19. Environmental Science Services Corporation, Newyork.

EPA, 1993. Constructed wetlands for wastewater treatment and wild life habitat: 17 Case Studies. United States Environmental Protection Agency, EPA832-R-93- 005.

EPA, 1999. Manual, Constructed Wetlands Treatment of Municipal Wasterwaters, EPA/625/R-99/010, U.S. Environmental Protection Acency, Cincinnati, Ohio, USA.

Garcia, J., Aguirre, P., Mujeriego, R., Huang, Y., Ortiz, L., Bayona, J.M., 2004. Initial contaminant removal performance factors in horizontal flow reed beds used for treating urban wastewater, Water Research, 38: 1669-1678.

Kadlec, H.R., and Knight, R.L., 1996. Treatment Wetlands. Lewis Publisher. FL. USA.

Mann, R.A., 1994. Phosphorus Removal in Constructed Wetlands: Substratum adsorption, Pergamon Press, Oxford, s. 97-105.

Maden Tetkik ve Araştırma Genel Müdürlüğü. MTA. (http://www.mta.gov.tr), (Erişim Tarihi: Nisan 2018)
Masscheleyn, P. H., J. H. Pardue, R. D. DeLaune, and W. H. Patrick, Jr., 1992. Phosphorus release and assimilatory capacity of two lower Mississippi Valley freshwater wetland soils, Wat. Res. Bul., 28: 763773.

Njau, K.N., Minja, R.J., Katima, J.H., 2003. Pumice Soil: A Potential Wetland Substrate for Treatment of Domestic Wastewater, Water Science and Technology, 48 (5):85/92.

Onar, A. N., Öztürk, B., 1993. Adsorption of Phosphate onto Pumice Powder, Environmental Technology, 14 (11): 1081-1087.

Reedy, K.R., D’Angelo E.M., 1994. Constructed wetland specifications for pollutant removal, Wat.Sci and Tech., 35 (5): 1-10.

Sakadevan, K., H. J. Bavor., 1998. Nutrient removal mechanisms in Constructed Wetlands, Water Resarch, 32 (2): 393399.

Vymazal, J., Brix, H., Cooper, P.F., Haberl, R., Perfler, R., Laber, J., 1998. Removal mechanisms and types of constructed wetlands. Constructed wetlands for wastewater treatment in Europe, s. 1766. 